University of Nebraska - Lincoln

DigitalCommons@University of Nebraska - Lincoln

USDA Forest Service / UNL Faculty Publications U.S. Department of Agriculture: Forest Service -National Agroforestry Center

2012

\title{
Adaptive Divergence at the Margin of An Invaded Range
}

Francis F. Kilkenny

University of Virginia, ffkilkenny@fs.fed.us

Laura F. Galloway

University of Virginia, Igalloway@virginia.edu

Follow this and additional works at: https://digitalcommons.unl.edu/usdafsfacpub

Kilkenny, Francis F. and Galloway, Laura F., "Adaptive Divergence at the Margin of An Invaded Range" (2012). USDA Forest Service / UNL Faculty Publications. 226.

https://digitalcommons.unl.edu/usdafsfacpub/226

This Article is brought to you for free and open access by the U.S. Department of Agriculture: Forest Service -National Agroforestry Center at DigitalCommons@University of Nebraska - Lincoln. It has been accepted for inclusion in USDA Forest Service / UNL Faculty Publications by an authorized administrator of DigitalCommons@University of Nebraska - Lincoln. 


\title{
ADAPTIVE DIVERGENCE AT THE MARGIN OF AN INVADED RANGE
}

\author{
Francis F. Kilkenny ${ }^{1,2,3}$ and Laura F. Galloway ${ }^{1}$ \\ ${ }^{1}$ Department of Biology, University of Virginia, Charlottesville, VA 22904-4328 \\ ${ }^{2}$ Current address: USDA Forest Service, Pacific Northwest Research Station, Corvallis, OR 97331-8550 \\ ${ }^{3}$ E-mail: ffkilkenny@fs.fed.us
}

Received August 12, 2010

Accepted September 22, 2012

Data Archived: Dryad doi:10.5061/dryad.6b2t6

\begin{abstract}
Invasive plant species threaten biological communities globally. However, relatively little is known about how evolutionary processes vary over the course of an invasion. To evaluate the importance of historical and adaptive drivers of range expansion, we compare the performance of North American populations of invasive Lonicera japonica from areas established 100-150 years ago, now the southern core of the range, to populations from the northern range margin, established within the last 65 years. Growth and survival of individuals from 17 core and 14 margin populations were compared in common gardens at both regions. After three years, margin plants were larger than core plants regardless of planting region, with $34 \%$ more branches and $36 \%$ greater biomass. Growth rate was directly related to survival, and margin plants also had $30 \%$ greater survival than core plants across both regions. Larger size of individuals from margin populations suggests either that the shorter growing period at the northern margin has selected for more rapid growth or that range expansion has selected for plants with a greater colonizing ability, including rapid establishment and growth. Because this evolution has resulted in enhanced survival and increased growth rate it may drive spread, increasing the likelihood of further invasion.
\end{abstract}

KEY WORDS: common garden, invasive species, range limits, range expansion, plasticity, local adaptation, genetic drift, countergradient selection.

Invasive plant species rapid spread is due to ecological and evolutionary changes relative to populations in their native range (Sakai et al. 2001). However, relatively little is known about how evolutionary processes shaping invasive populations vary throughout the history of an invasion or across the invaded range (e.g. Siemann and Rogers 2001; Lankau et al. 2009). Attempts to characterize biological invasion in a historical context have viewed it as a multistage process (Lodge 1993; Sakai et al. 2001; Theoharides and Dukes 2007; Gurevitch et al. 2011), where the evolution of invading populations is expected to shift from being driven primarily by drift during early establishment and naturalization, to being driven primarily by selection as that population reaches higher abundance (Sakai et al. 2001; Dietz and Edwards 2006). Similarly, the processes contributing to invasion are also expected to vary spatially, such that across the range the importance of nonadaptive processes and the types of selection pressures that invasive populations experience vary (Burton et al. 2010). This suggests species will be a mosaic of evolutionary outcomes across their invaded range, depending on historical events and location. To understand the evolutionary processes involved in range expansion, studies are needed that compare populations of different ages and from spatially distinct areas within the expanding range (Colautti et al. 2009; Monty and Mahy 2009).

Spatially based phenotypic variation can arise in several ways during plant invasions. First, as individuals move into new areas, local selection is expected to operate on plant traits by favoring individuals that can thrive under novel biotic and abiotic conditions (Parker et al. 2003). Indeed, common garden experiments 
and patterns of genetic differentiation have shown rapid evolution in invasive plant species that can lead to populations becoming locally adapted along environmental clines (e.g. Maron et al. 2004; Leger and Rice 2007; Alexander et al. 2009; Kooyers and Olsen 2012). Adaptation to novel environments will happen as species expand in the invaded range (see Kawecki and Ebert 2004). This process of local adaptation can play a role in range expansion, because adaptation to conditions at a range edge will lead to increased reproduction and further spread. Conversely, limits to further invasion may be due to a failure of populations to adapt to conditions beyond the leading-edge of the expansion (Holt 1996; Alexander and Edwards 2010; Anderson and Geber 2010; Coulatti et al. 2010).

Second, the process of invasion and range expansion may select for traits that promote colonization itself, including traits that enhance dispersal (Simmons and Thomas 2004; Phillips et al. 2006, 2010; Monty and Mahy 2010) and interspecific competitive advantage (Lankau et al. 2009). As such, ecological and evolutionary processes at an expanding range edge might differ from processes within the established core of an invader's range (Sexton et al. 2009). For example, selection for traits that increase colonization success may be favored at the range edge, but not the core of the range (Geber 2008; Philips et al. 2010). Selection for dispersal characteristics, in particular, may depend on whether the range edge is static, variable (Darling et al. 2008), or still expanding (Sexton et al. 2009). Traits that promote selfing, including vegetative reproduction and increased self-compatibility (Darling et al. 2008), may also be favored at the range edge, particularly if populations are at low abundance and Allee effects are common (Baker 1955). The advantage of vegetative reproduction is that genotypes may be able to persist well after establishment and wait for mates. In contrast, populations in the core of a species range may face much higher intraspecific competition than populations at the range edge (Lankau et al. 2009). This is especially true for species that reach very high densities. As a result, how selection acts on competitive traits may differ between the established and expanding areas of the invaded range. However, to date few studies have considered this issue so it is difficult to determine how widespread this phenomenon is.

Finally, nonadaptive evolution may also occur during invasion (Keller et al. 2009). For example, genetic drift is likely to result from the repeated founder events and bottlenecks (Barrett and Husband 1990; Parker et al. 2003; Oliveri 2009). In addition, propagules are more likely to establish in climates similar to home. As a result, apparent adaptive evolution within the invaded range may simply reflect differential establishment success in the invaded habitat (Maron et al. 2004; Monty and Mahy 2009). Genetic information can be used to evaluate whether observed phenotypic differences between invasive populations are due to sampling processes, therefore reflecting source populations, or to selection in the invaded range (Keller and Taylor 2008).

To determine the role of adaptation in range expansion, this study compares performance of North American populations of the invasive vine Japanese honeysuckle (Lonicera japonica) in regionally specific common gardens. Populations from the older core (established 100 to 150 years ago) were compared to populations from the recently colonized margin (established within the last 65 years). We ask, are there evolutionary differences between core and margin populations? If so, are differences due to local adaptation or other processes, such as the evolution of traits that promote colonization? Alternatively, are any differences between older core and more recently established margin populations due to the genetic source of the populations?

\section{Methods STUDY SYSTEM}

Lonicera japonica Thunb. (Caprifoliaceae) is a woody vine native to Japan, China, and Korea that invades natural and managed habitats throughout the United States and worldwide (Schierenbeck 2004). In the United States, it is considered a major pest by the forestry industry as well as state and federal governments (Skulman et al. 2004). Lonicera japonica was first introduced to Long Island, New York in 1806 (Leatherman 1955; Nuzzo 1997). Throughout the 19th century additional horticultural varieties were introduced and widely planted in gardens throughout the United States. The species has since become naturalized throughout eastern North America, particularly in the southeastern states where the first major invasions occurred (Nuzzo 1997; Schierenbeck 2004). Lonicera japonica's spread has continued northward in the last half century (Fig. 1; Beans et al. 2012).

Lonicera japonica is a long-lived clonal species that spreads locally through vegetative propagation, and geographically through seed dispersal by birds and other animals in addition to horticultural use (Schierenbeck 2004). Lonicera japonica is considered a strong competitor due to its highly plastic growth form (Larson 2000). Plants can develop roots and shoots at any node, allowing for complex architectures. When spreading laterally across flat surfaces, shoots will run straight, but shoots will twine upwards toward the light when they encounter obstacles, such as other plants. Lonicera japonica has sporophytic selfincompatibility, so several genotypes must establish in invaded areas before sexual reproduction can occur and generate seeds for dispersal and potential further spread (Schierenbeck 2004).

\section{EXPERIMENTAL DESIGN}

To test the contribution of local adaptation to L. japonica's continued range expansion, plants from the core and the margin of the 


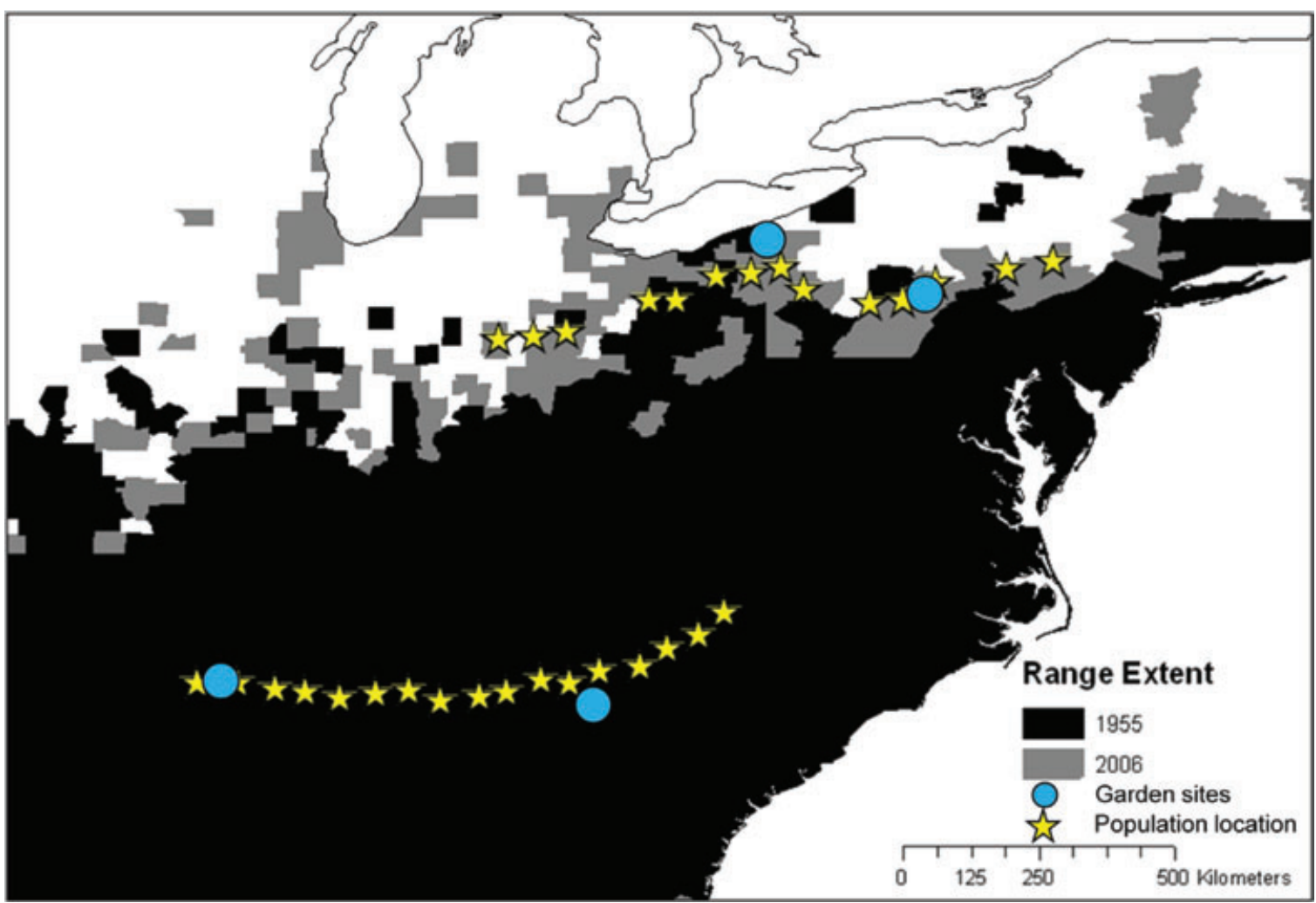

Figure 1. Range expansion of invasive Lonicera japonica since 1955. A 1955 range map from Leatherman 1955. A 2006 range map produced from field collections as well as 786 herbarium accessions from 24 herbariums (see Beans et al., 2012). Population locations are depicted by stars, garden sites by circles.

range were compared in both areas. Lonicera japonica cuttings were collected in June and July of 2006 along two east-west geographic transects differing in their latitude. One transect was in the northeastern United States, along the range margin $\left(40-41.3^{\circ} \mathrm{N}\right.$; Fig. 1), and the second was in the southeastern United States in the core of the range $\left(34.4-35.5^{\circ} \mathrm{N}\right.$; Fig. 1). Populations were sampled at roughly $50-\mathrm{km}$ intervals for a total of 14 populations from the margin and 17 populations from the core. Individuals from seven other locations along the margin were also included in the experiment and treated as separate populations. Within each population, large cuttings from individuals were collected at a minimum sampling distance of $50 \mathrm{~m}$ to avoid sampling multiple ramets of the same genet (Schierenbeck et al. 1995; Larson 2000). Four to ten genets were collected per population, and 211 genets were collected in total. Each genet was clonally replicated by dividing stems into eight cuttings with three to five nodes, treating each with rooting hormone (Hormex No. 3), and placing them in pots of perlite under intermittent mist for one month. Rooted cuttings were transferred to individual pots and kept in greenhouse conditions at the University of Virginia for approximately 3 months until they were planted into the field.

Lonicera japonica clones were planted out at two garden locations in the core of the range (Plant Sciences Farm at the
University of Georgia, and University of Mississippi Field Station; Fig. 1) and two garden locations at the margin of the range (Russell E. Larson Agricultural Research Farm at Pennsylvania State University, and Pymatuning Laboratory of Ecology run by the University of Pittsburgh; Fig. 1). All gardens were located in old fields, similar to habitat L. japonica might colonize. All established clones (2-8 per genotype, 1178 total) were distributed as evenly as possible across gardens. Therefore each sampled individual was represented at a given garden by $0-2$ clones, and each population was represented by approximately nine individuals per garden ( $8.8 \pm 2.7 \mathrm{SD})$. Plants were spaced 1-m apart, which kept intraspecific competition to a minimum. Prior to planting, the longest shoot was measured and the number of branches greater than $2 \mathrm{~cm}$ was counted on each plant. All gardens were prepared by mowing local vegetation prior to planting. After the initial mowing, all plants were allowed to experience natural competition. Deer fencing was erected at each garden, and all experimental plants were watered once, immediately following transplant. Plants were put into the ground at both margin gardens in the third week of October 2006, and at both core gardens in the first week of November 2006. Transplant survival was recorded at all gardens in the fourth week of November 2006. Only plants that survived transplanting were included in the analyses (1058 total). 
Survival and growth were monitored in the spring (late May or early June) and fall (late October or early November) of each year for the duration of the study (fall 2006 to spring 2009). The number of nodes on the longest shoot, the number of branches greater than $2 \mathrm{~cm}$, and the longest leaf were measured on each plant. Survival was also recorded. Because the shoots of plants occasionally died back to the root crown they were not always visible on inspection, therefore the location of each plant was checked during each visit for the entire duration of the study. All remaining plants were harvested from each garden in May of 2009 and were dried and weighed for above-ground biomass. Only four plants flowered across all gardens in the spring of 2009, and no plants flowered prior to that. Therefore, results are limited to vegetative traits.

\section{GENETIC CHARACTERIZATION}

To evaluate whether nonrandom sampling contributed to regional phenotypic differences, individuals were characterized with neutral genetic markers (Kilkenny 2011). All material was genotyped using standard protocols for Amplified Fragment Length Polymorphisms (AFLPs; Vos et al. 1995; Applied Biosystems 2005). Three primer pairs were selected based on the number of polymorphic loci (EcoR-ACT/Mse-CTA: 65 loci, EcoR-ACC/Mse-CAT: 54 loci, and EcoR-AAG/Mse-CAG: 102 loci). Samples were run on an automated sequencer with peaks sized against a known standard, and individuals were scored for the presence or absence of alleles using the Genemapper program (Applied Biosystems 2005). Program STRUCTURE was used to estimate the number of genetic groups within the dataset and probabilistically assign each individual to a genetic group (Pritchard et al. 2000). The best fit model, four genetic groups, was determined using the methods of Evanno et al. 2005 (Fig. S1). Genetic group was included in the statistical analysis to determine whether genetic history accounts for variation in performance.

\section{STATISTICAL ANALYSIS}

Evolutionary differences between populations from the core and margin of L. japonica's invaded range were evaluated using a generalized linear mixed model (PROC GLIMMIX; SAS Institute 2009). Final survival, the probability of plants surviving throughout the entire experiment, was assumed to follow a binomial distribution. Planting region (region) and region of origin (origin) were included in the model as main effects. Genetic group, ascertained through neutral genetic markers (Kilkenny 2011), was also included as a main effect to account for genetic differences that predate invasion (Keller and Taylor 2008). The region $\times$ origin interaction was tested to determine whether plants from the core and margin were locally adapted to their respective habitats (Kawecki and Ebert 2004). The origin $\times$ genetic group interaction evaluates whether survival differences between genetic groups depended on whether the populations were from the core or margin of the range. The random variables of population nested in origin, garden location (site) nested in region, region $\times$ population (nested in origin), and genetic group $\times$ population (nested in origin) were also included. To test for differences in survival patterns between seasons, mortality was coded as either summer or winter for each plant. Separate analyses were then performed on summer and winter survival.

Differences in growth rate may determine reproductive fitness later in life as well as be important to vegetative spread. To determine whether growth rate differences between plants from the core and plants from the margin reflected local adaptation, a MANOVA was performed with all final size estimates including node number, branch number, leaf length, and biomass (PROC MIXED; SAS Institute 2009). The MANOVA used a model analogous to the above analysis of survival. Number of branches at planting (initial size) was included in the model as a covariate. The interactions initial size $\times$ region and initial size $\times$ origin were tested, but were not found to be significant and so met the assumptions of a covariate. The canonical structures of region, origin, and genetic group were also determined.

We tested whether differences in survival might be related to plant size during selective events using a Generalized Estimating Equations model (GEE; PROC GENMOD). A GEE model can be used as a repeated measures ANOVA in cases where the dependent variable is binary, as with survival data. Census date, prior size, origin, and region were included in the model as independent variables, as were all pairwise interactions. The number of branches at the previous census was used as a measurement of prior size. The number of plants represented per prior transition period ranged from 890 (fall 2006-spring 2007) after the first transition to 396 after the last transition (fall 2008-spring 2009).

\section{Results}

Plants originating from the range margin (margin plants) had greater survival in both the core and the margin than plants originating from the core of the range (core plants). In the final survival analysis, origin was the only significant factor (Table 1A), with margin plants having $30 \%$ greater final survival than core plants (Fig. 2A). Although overall survival was independent of planting region, when summer and winter survival were analyzed separately, region affected survival in winter and had a near-significant effect on survival in summer (Table 1B). However, the direction of the region effect on survival depended on whether mortality occurred in the summer or winter (Fig. 2B, C). For plants grown in the core region, survival was high in the winter and nearly all deaths occurred during the summer, while the opposite was true for plants grown in the margin region with high summer survival and nearly all mortality occurring in the winter. Survival was 
Table 1. Generalized linear mixed model for (A) final survival and (B) survival over the summer and winter for Lonicera japonica originating from the core and margin of the invaded range and grown at two common gardens in the core region and two common gardens in the margin region of the range. Random variables for analysis of variance were not significant and are not shown (see text for details).

\begin{tabular}{llll}
\hline Source & df & $F$ & $P$ \\
\hline A. Final Survival & & & \\
$\quad$ Region & 1,2 & 0.13 & 0.75 \\
Origin & 1,30 & 6.40 & 0.02 \\
Genetic group & 3,767 & 2.01 & 0.11 \\
Region $\times$ origin & 1,30 & 1.54 & 0.22 \\
Origin $\times$ group & 3,767 & 2.29 & 0.08 \\
B. Seasonal survival & & & \\
Summer & & & \\
Region & 1,2 & 11.50 & 0.08 \\
Origin & 1,30 & 2.64 & 0.11 \\
Genetic group & 3,771 & 0.66 & 0.58 \\
\hline Region $\times$ origin & 1,30 & 2.94 & 0.10 \\
Origin $\times$ group & 3,771 & 1.25 & 0.29 \\
Winter & & & \\
Region & 1,2 & 46.76 & 0.02 \\
Origin & 1,30 & 6.58 & 0.02 \\
Genetic group & 3,771 & 1.89 & 0.13 \\
\hline Region $\times$ origin & 1,30 & 0.04 & 0.85 \\
\hline Origin $\times$ group & 3,771 & 2.40 & 0.07 \\
\hline
\end{tabular}

greater for margin plants than core plants in the winter (Table 1B; Fig. 2C).

Plants from the margin were larger, and thus had faster growth rates, than those from the core regardless of planting region (Table 2 , Fig. 3). Margin plants had on average $8 \%$ more nodes (Fig. 3A), 34\% more branches (Fig. 3B), and 36\% greater biomass (Fig. 3C) than plants from the core of the invaded range. Plants were also larger when grown in the core region (Table 2, Fig. 3 ). The canonical structures indicated that node number, branch number, and biomass were all important to region and origin size differences, but not leaf length (Table 2). In contrast, there was no region by origin interaction, nor did genetic group affect size characters (Table 2).

Size was directly related to survival. In the GEE model, plants that were larger in the period prior to the survival measurement had greater survival than plants that were smaller (Table 3, Fig. 4). This relationship varied through time and by region. In general, the effect of prior size on survival increased through time, but the difference in size between plants that lived and those that died was greater in the core than at the margin (Fig. 4). Note that when size was accounted for, plant origin did not have an effect on survival but planting region did.
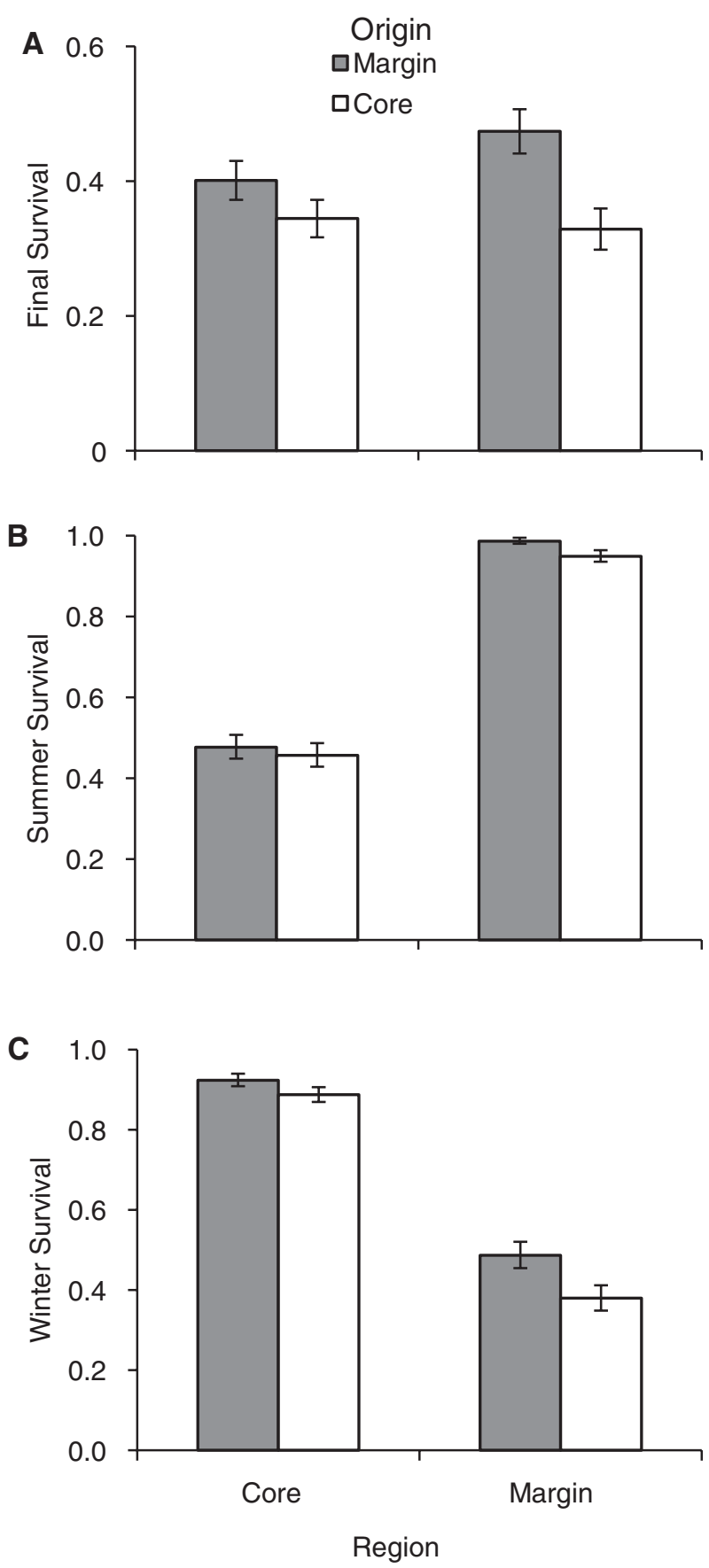

Figure 2. Final, summer and winter survival for Lonicera japonica originating from the core and margin of the invaded range and grown at two common gardens in the core region and two common gardens in the margin region of the range. All values reported as least square means. See Table 1 for statistical details.

\section{Discussion}

The classical pattern of local adaptation, where populations are most adapted to their home environment, was not observed in $L$. japonica's invaded North American range. Plants from margin populations had higher survival in both regions, and the origin 
Table 2. Multivariate analysis of variance of size traits of Lonicera japonica originating from the core and margin of the invaded range and grown at two common gardens in the core region and two common gardens in the margin region of the range. Node number, branch number, biomass, and leaf length were included in the analysis. The canonical structure is given to illustrate the contribution of size traits to the effects of planting region and origin.

\begin{tabular}{lllrl}
\hline Source & df & Wilks' $\lambda$ & $F$ ratio & $P$ \\
\hline Initial size & 4,223 & 0.94 & 3.62 & $<0.01$ \\
Region & 4,223 & 0.76 & 17.14 & $<0.0001$ \\
\hline Origin & 4,27 & 0.68 & 3.21 & 0.03 \\
Genetic group & 12,590 & 0.96 & 0.82 & 0.63 \\
Region $\times$ origin & 4,23 & 0.85 & 1.05 & 0.40 \\
Origin $\times$ group & 12,48 & 0.61 & 0.83 & 0.62 \\
Site(region) & 8,446 & 0.68 & 11.68 & $<0.0001$ \\
Population(origin) & 120,889 & 0.55 & 1.20 & 0.09 \\
Region $\times$ pop(origin) & 104,887 & 0.66 & 0.95 & 0.62 \\
Group $\times$ pop(origin) & 84,883 & 0.68 & 1.09 & 0.28 \\
\hline
\end{tabular}

Canonical structure

\begin{tabular}{lll}
\cline { 2 - 3 } Trait & Region & Origin \\
\hline Node number & 0.87 & 0.72 \\
Branch number & 0.68 & 0.84 \\
Biomass & 0.36 & 0.76 \\
Leaf length & 0.27 & 0.10 \\
\hline
\end{tabular}

$\times$ region interaction was not significant in the survival analyses. The higher survival of margin plants persisted even when regional winter and summer differences were considered. At the range margin, winter mortality events were regular occurrences suggesting that there was selection for plants that are more tolerant to cold conditions. In the core of the range, most summer mortality occurred in a single year during a period of extreme drought, suggesting that surviving plants might be selected to be more drought tolerant. Margin plants had greater survival in the winter, indicating that they were likely to be more cold tolerant than core plants. Plants from both regions were similarly affected by drought. These findings differ from studies that show plants evolving to match environmental clines in their invaded range (e.g. Maron et al. 2004), and suggest that adaptation to local conditions by both core and margin plants may be only a partial driver of the survival differences in this system.

Plant growth rate also showed no evidence of reciprocal local adaptation. At the end of the experiment, plants originating from the range margin were larger, with more branches and greater biomass, than plants from the core of the range regardless of where they were planted. These origin-based differences in growth rate, and the lack of significant interactions between population origin and planting region, do not support local adaptation to both core and margin regions for these traits. Differences in survival were at least in part driven by size during selective events. Plant size in the previous time interval was a strong predictor of survival.

It is possible that these differences in phenotype between populations from the core and margin of the range may be due to nonadaptive processes, such as drift acting through founder effect or colonization history. Genetic information can help differentiate adaptive processes within the invaded range from changes due to nonrandom sampling of plants from the native range (Keller and Taylor 2008). In other work, we found that genetic structure across the range is weak, with the majority of genetic variation occurring within and among populations, but not between core and margin regions (Kilkenny 2011). Specifically, populations are composed of one to four genetically distinct groups, and these groups are widely distributed throughout populations in both the core and the margin. Here we tested the contribution of these genetic groups to both survival and growth rate and found no difference among groups in either case. Given this finding, it is unlikely that the observed phenotypic differences between the core and margin populations are due to sampling processes associated with colonization history that resulted in a nonrandom distribution of source genetic types. Instead, differences in survival and growth rate are likely due to regional patterns of selection.

The faster growth rate of margin plants sampled across many populations, expressed both in the core and margin gardens, strongly suggests adaptive differentiation. However, the selective pressures underlying this difference are unclear. One possibility is that there are differences in competitive environments between the core and margin that favor different traits (e.g. Burton et al. 2010). This study was conducted in an open-field environment where interspecific competition included grasses and herbaceous plants, but there was no intraspecific competition. Open-field conditions bear a closer resemblance with the margin habitats where L. japonica densities are low (25\% cover), than the core habitats where intraspecific densities are high (60\% cover; see Kilkenny 2011). Therefore, if there has been adaptation to areas with low intraspecific competition at the range margin, the open-field conditions may favor margin plants. Further, L. japonica branches can both twine and run straight across flat surfaces (Larson 2000). The open-field conditions of this study may have promoted the success of genotypes that produce runners and have a spreading growth form relative to genotypes that produce climbing stems. Greater intraspecific competition in the core may select for a greater tendency to climb as it would increase competitive ability. However, contrary to these predictions, a common garden study found no difference in the tendency to twine between core and margin populations, and that margin plants had greater intraspecific competitive abilities, apparently due to their larger size (Evans et al., unpubl. ms.). Therefore, there is little support for 

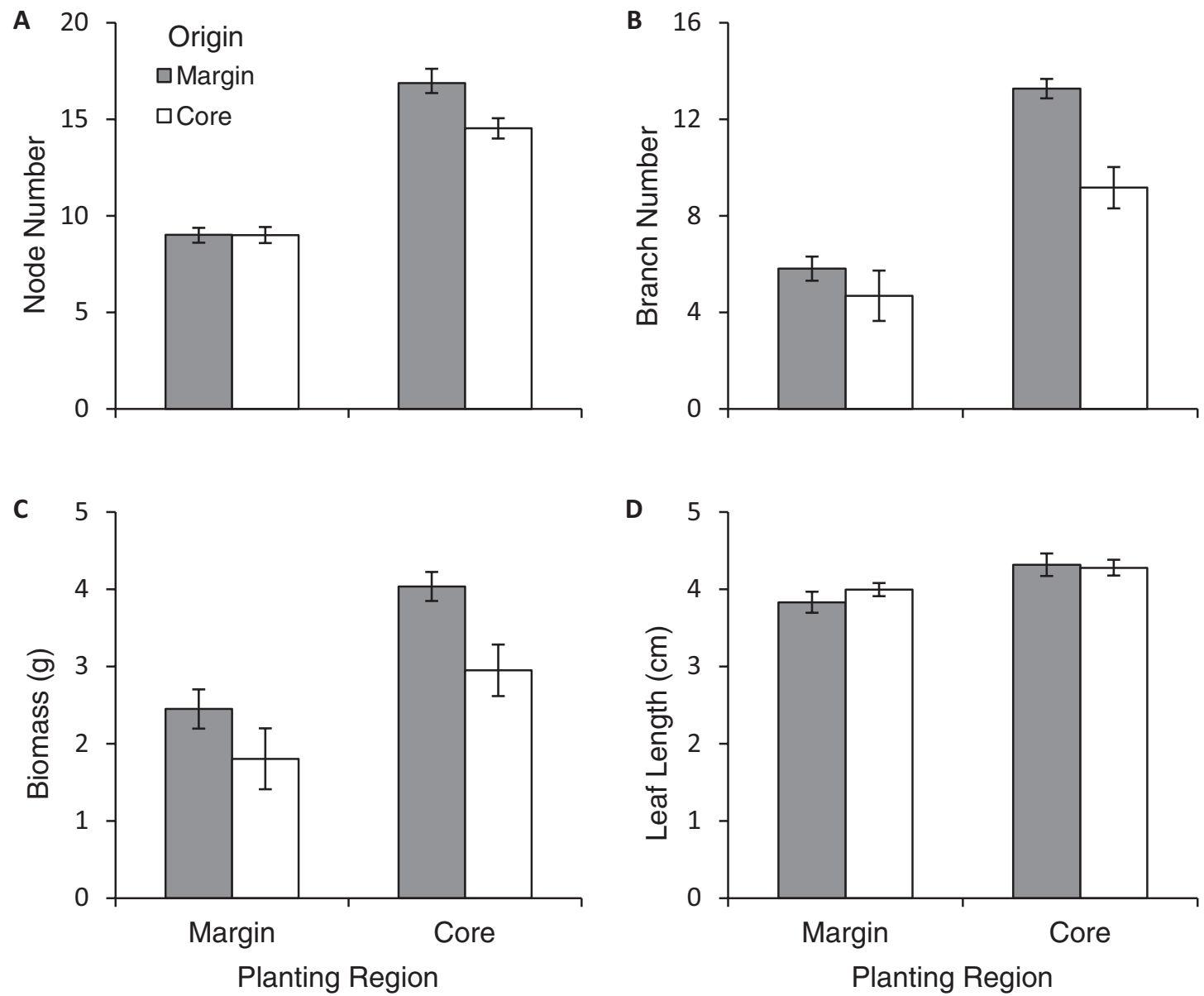

Figure 3. Final node number (A), branch number (B), biomass (C), and leaf length (D) for Lonicera japonica originating from the core and margin of the invaded range and grown at two common gardens in the core region and two common gardens in the margin region of the range. All values reported as least square means. See Table 2 for statistical details.

differential competitive regimes across the range causing the observed differentiation.

Larger size or faster growth rates may evolve after enemy release (Blossey and Nötzold 1995). It is possible that natural enemies have accumulated in the older core over time and plants from the core have undetected trade-offs between growth traits and traits that protect against natural enemies (Siemann and Rogers 2001); in which case their slower growth rate may be the result of these trade-offs. If this is the case, margin plants should be at a disadvantage in the core gardens, where natural enemies, including herbivores and soil pathogens, should be abundant. However, margin plants performed better than core plants in the core gardens. In addition, detectable insect herbivore damage occurred only in one year (2007) and in one core garden (Mississippi) over the course of this study (unpublished data), suggesting that herbivory is not a ubiquitous component of this system. There is also no reason to believe that plants at the margin experience more interspecific competition than plants in the core, considering that plant biomass tends be similar across the latitudes represented in this study (Enquist and Niklas 2001). Taken together, this suggests that the larger size of margin plants was not due to evolutionary trade-offs after enemy release or to the direct competitive advantages that size might confer.

Alternatively, the greater final size of margin plants found in this study may be an evolutionary response to selection for more rapid growth in the shorter seasonal growing periods at the range margin. Although final plant size was greater for individuals that originated in the range margin, plants grown in the core habitat were substantially larger than those grown in the range margin regardless of origin. This countergradient variation, when the pattern of genetic variation opposes that of ecological variation, has been observed when growth rates differ across habitats (Conover and Schultz 1995; Laugen et al. 2003; Etterson 2004). When selection for traits that oppose an ecological gradient occurs in a fitness trait, such as size or growth rate in clonal plants, the expected observation of local adaptation causing trade-offs in performance in different environments is not typically found (Conover and Schultz 1995). Therefore, although size during 
Table 3. Generalized estimating equations model for the effect of size, measured as branch number, for the prior census period on survival of Lonicera japonica originating from the core and margin of the invaded range and grown at two common gardens in the core region and two common gardens in the margin region of the range.

\begin{tabular}{lrrc}
\hline Source & Estimate & \multicolumn{1}{c}{$Z$} & $P$ \\
\hline Date & 0.04 & 0.60 & 0.55 \\
Prior size & 0.13 & 2.01 & 0.05 \\
Region & -1.09 & -5.11 & $<0.0001$ \\
Origin & 0.10 & 0.57 & 0.57 \\
Date $\times$ prior size & -0.12 & -4.88 & $<0.0001$ \\
Date $\times$ region & 0.10 & 1.58 & 0.11 \\
Date $\times$ origin & -0.11 & -2.02 & 0.04 \\
Prior size $\times$ region & 0.27 & 5.38 & $<0.0001$ \\
Prior size $\times$ origin & -0.01 & -0.13 & 0.90 \\
Region $\times$ origin & -0.02 & -0.14 & 0.89 \\
\hline
\end{tabular}

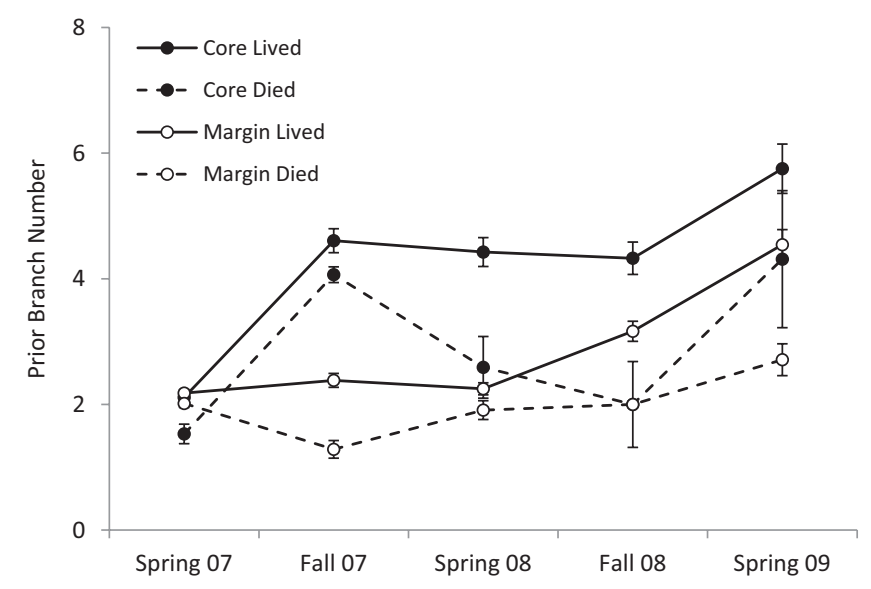

Figure 4. Branch number at the previous census and whether plants lived or died for twice annual censuses through the study period for Lonicera japonica. See Table 3 for statistical details.

selective events increased $L$. japonica survival in both the core and the margin, the rapid growth rates that confer this size advantage may have only been selected for at the margin.

It should be noted that selection for later life-history traits that trade-off with growth rate in the core of the range could generate a similar pattern. This may be true if the traits in question are both fitness traits; for example, a trade-off between early vegetative growth and later flower production. Because plants in this study produced almost no flowers, we cannot say from these data whether a trade-off of this sort is present in L. japonica. However, another study, conducted under more favorable growing conditions, suggests that greater vegetative growth also leads to greater flower production (Evans et al., unpubl. ms.). There is also a possibility that slower growth rate in the core has been selected for by periodic stressors, such as drought. Although we cannot be certain how all possible periodic stresses might operate over the lifetime of such a long-lived plant, a substantial drought did occur in the core gardens during this study and core plants did not demonstrate any apparent benefit.

A final explanation for the greater final size of margin plants is that characters seen at the margin are traits that allow for rapid colonization (Phillips 2009, Philips et al. 2010). Because L. japonica can spread clonally, the faster growth rate of margin plants may reflect selection for localized clonal dispersal. Plants can root at any node along a branch, meaning that a greater number of branches would likely lead to a greater number of new rooting nodes, each of which can be a locus for localized spread. Clonal reproduction is especially important for L. japonica, because it is self-incompatible. Plants that grow in size rapidly would be better able to survive and would also have a reproductive advantage when new mates arrive. This suggests that the range expansion process may have selected for plants with greater ability to establish and spread clonally. The majority of colonizing traits described in the literature are traits that promote dispersal (Simmons and Thomas 2004; Phillips et al. 2006; Darling et al. 2008). In light of this, our finding is important given that it suggests that traits promoting establishment after dispersal may also be selected for during the colonization process. Though we should qualify this by pointing out that it is not possible for this study to separate selection based on colonization success, which should occur at any range margin regardless of geographical location, from selection based on latitudinal climates, because the range margin tested in this study was spread across a narrow latitudinal band. Nevertheless, establishment traits may be especially critical to the range expansion of long-lived and outcrossing species, and should be considered in other range expansion studies.

In summary, we found that plants from populations at the range margin were larger and therefore had greater rates of survival regardless of which area of the invaded range they were grown in. We suggest that this adaptive difference could be due to either selection for more rapid growth in northern areas with shorter growing seasons or the evolution of traits that enhance colonization success at the leading-edge of the range expansion. In fact, either or both of these explanations could underlie the observed adaptive differentiation in invasive L. japonica. The existence of multiple plausible hypotheses emphasizes the complexity of selective pressures that may give rise to adaptive evolution during range expansion in invasive species. The majority of empirical studies on evolution during range expansion have compared species in invaded versus native ranges (Bossdorf et al. 2005; Prentis et al. 2008). With the exception of clinal adaptation, only a handful of studies have considered dynamics within the invaded range (Phillips et al. 2006, 2010; Lankau et al. 2009). Therefore little is known about whether the patterns found for L. japonica are common. For this reason, further spatial comparisons within 
invasions as well as a broader comparison of older and younger invasions should be fruitful areas to direct future research.

\section{ACKNOWLEDGMENTS}

We wish to thank the Plant Sciences Farm at the University of Georgia, the University of Mississippi Field Station, the Russell E. Larson Agricultural Research Farm at Pennsylvania State University, and the Pymatuning Laboratory of Ecology for providing field sites. We are also grateful to E. Miller, B. Barringer, K. Burgess, A. Dai, and E. Yoshizuka for help in the field and greenhouse; to University of Virginia for providing greenhouse space; to W. Crannage for keeping the greenhouse running smoothly; to the Jeffress Foundation for funding; and to FFK's committee members and two anonymous reviewers for comments on previous drafts.

\section{LITERATURE CITED}

Alexander, J. M., and P. J. Edwards. 2010. Limits to the niche and range margins of alien species. Oikos 119:1377-1386.

Alexander, J. M., P. J. Edwards, M. Poll, C. G. Parks, and H. Dietz. 2009. Establishment of parallel altitudinal clines in traits of native and introduced forbs. Ecology 90:612-622.

Anderson, J. T., and M. A. Geber. 2010. Demographic source-sink dynamics restrict local adaptation in Elliott's blueberry (Vaccinium elliottii). Evolution 64:370-384.

Applied Biosystems. 2005. AFLP plant mapping protocol. Applied Biosystems, Foster City, CA.

Baker, H. G. 1955. Self-compatibility and establishment after long distance dispersal. Evolution 9:347-349.

Barrett, S. C. H., and B. C. Husband. 1990. Genetics of plant migration and colonization. In: Brown, A. H. D., M. T. Clegg, A. L. Kahler, and B. S. Weir, eds. Plant population genetics, breeding and genetic resources. Sinauer Associates, pp 254-277.

Beans, C. M., F. F. Kilkenny, and L. F. Galloway. 2012. Climate suitability and human influences combined explain the range expansion of an invasive horticultural plant. Biol. Invas. 14:2067-2078.

Blossey, B., and R. Nötzold. 1995. Evolution of increased competitive ability in invasive nonindigenous plants: a hypothesis. J. Ecol. 83:887-889.

Bossdorf, O., H. Auge, L. Lafuma, W. E. Rogers, E. Siemann, and D. Prati. 2005. Phenotypic and genetic differentiation between native and introduced plants populations. Oecologia 144:1-11.

Burton, O. J., B. L. Philips and J. M. J. Travis. 2010. Trade-offs and the evolution of life-histories during range expansion. Ecol. Lett. 13:1210 1220.

Colautti, R. I., J. L. Maron, and S. C. H. Barrett. 2009. Common garden comparisons of native and introduced plant populations: latitudinal clines can obscure evolutionary inferences. Evol. Appl. 2:187-199.

Coulatti, R. I., C. G. Eckert, and S. C. H. Barrett. 2010. Evolutionary constraints on adaptive evolution during range expansion in an invasive plant. Proc. R. Soc. Lond. B. 277:1799-1806.

Conover, D. O., and E. T. Schultz. 1995. Phenotypic similarity and the evolutionary significance of countergradient variation. Trends Ecol. Evol. 10:248-252.

Darling, E., K. E. Samis, and C. G. Eckert. 2008. Increased seed dispersal potential towards geographic range limits in a Pacific coast dune plant. New Phytol. 178:424-435.

Dietz, H., and P. J. Edwards. 2006. Recognition that causal processes change during plant invasion helps explain conflicts in evidence. Ecology 87:1359-1367.

Enquist, B. J., and K. J. Niklas. 2001. Invariant scaling relations across treedominated communities. Nature 410:655-741.
Etterson, J. R. 2004. Evolutionary potential of Chamaecrista fasciculata in relation to climate change. 1. Clinal patterns of selection along an environmental gradient in the Great Plains. Evolution 58:1446-1458.

Evanno, G., S. Regnaut, and J. Goudet. 2005. Detecting the number of clusters of individuals using the software STRUCTURE: a simulation study. Mol. Ecol. 14:2611-2620.

Geber, M. A. 2008. To the edge: studies of species' range limits. New Phytol. 178:228-230.

Gurevitch, J., G. A. Fox. G. M. Wardle, Inderjit, and D. Taub. 2011. Emergent insights from the synthesis of conceptual frameworks for biological invasions. Ecol. Lett. 14:407-418.

Holt, R. D. 1996. Demographic constraints in evolution: towards unifying the evolutionary theories of senescence and niche conservatism. Evol. Ecol. 10:1-11.

Kawecki, T. J., and D. Ebert. 2004. Conceptual issues in local adaptation. Ecol. Lett. 7:1225-1241.

Keller, S. R., and D. R. Taylor. 2008. History, chance and adaptation during biological invasion: separating stochastic phenotypic evolution from response to selection. Ecol. Lett. 11:852-866.

Keller, S. R., D. R. Sowell, M. Neiman, L. M. Wolfe, and D. R. Taylor. 2009. Adaptation and colonization history affect the evolution of clines in two introduced species. New Phytol. 183:678-690.

Kilkenny, F.F. 2011. Gene flow and adaptation in Lonicera japonica. Ph.D. Dissertation, University of Virginia, Charlottesville, VA.

Kooyers, N. J. and K. M. Olsen. 2012. Rapid evolution of an adaptive cyanogenesis cline in introduced North American white clover (Trifolium repens L.). Mol. Ecol. 21:2455-2468.

Lankau, R. A., V. Nuzzo, G. Spyreas, and A. S. Davis. 2009. Evolutionary limits ameliorate the negative impact of an invasive plant. Proc. Natl. Acad. Sci. USA 106:15362-15367.

Larson, K. C. 2000. Circumnutation behavior of an exotic honeysuckle vine and its native congener: influence on clonal mobility. Am. J. Bot. 87:533538.

Laugen, A. T., A. Laurila, K. Räsänen, and J. Merilä. 2003. Latitudinal countergradient variation in the common frog (Rana temporaria) development rates_evidence for local adaptation. J. Evol. Biol. 16:999-1005.

Leatherman, A. D. 1955. Ecological life-history of Lonicera japonica Thunb. $\mathrm{Ph}$. D. dissertation, University of Tennessee, Knoxville, TN.

Leger, E. A., and K. J. Rice. 2007. Assessing the speed and predictability of local adaptation in invasive California poppies (Eschscholzia californica). J. Evol. Biol. 20:1090-1103.

Lodge, D. M. 1993. Species invasions and deletions: community effects and responses to climate and habitat change. In: Karieva, P. M., J. G. Kingsolver, and R. B. Huey, eds. Biotic Interactions and Global Change. Sinauer Associates, pp 367-387.

Maron, J. L., M. Vilà, R. Bommarco, S. Elmendorf, and P. Beardsley. 2004. Rapid evolution of an invasive plant. Ecol. Monogr. 74:261-280.

Monty, A., and G. Mahy. 2009. Clinal differentiation during invasion: Senecio inaequidens (Asteraceae) along altitudinal gradients in Europe. Oecologia 159:305-315.

- 2010. Evolution of dispersal traits along an invasion route in the wind-dispersed Senecio inaequidens (Asteraceae). Oikos 119:15631570.

Oliveri, I. 2009. Alternative mechanisms of range expansion are associated with different changes of evolutionary potential. Trends Ecol. Evol. 24:289-292.

Nuzzo, V. 1997. Element stewardship abstract for Lonicera japonica. The Nature Conservancy, Arlington, VA. 22 p.

Parker, I. M., J. Rodriguez, and M. Loik. 2003. An evolutionary approach to understanding the biology of invasions: local adaptation and 
general purpose genotypes in the weed Verbascum thapsus. Conserv. Biol. 17:59-72.

Phillips, B. L. 2009. The evolution of growth rates on an expanding range edge. Biol. Lett. 5:802-804.

Phillips, B. L., G. P. Brown, J. K. Webb, and R. Shine. 2006. Invasion and the evolution of speed in toads. Nature 439:803.

Phillips, B. L., G. P. Brown, and R. Shine. 2010. Life-history evolution in range-shifting populations. Ecology 91:1617-1627.

Prentis, P. J., J. R. U. Wilson, E. E. Dormontt, D. M. Ricardson, and A. J. Lowe. 2008. Adaptive evolution in invasive species. Trends in Plant Sci. 13:288-294.

Pritchard, J. K., M. Stephens, and P. Donnelly. 2000. Inference of population structure using multilocus genotype data. Genetics 155: 945-959.

Sakai, A. K., F. W. Allendorf, J. S. Holt, D. M. Lodge, J. Molofsky, K. A. With, S. Baughman, R. J. Cabin, J. E. Cohen, N. C. Ellstrand et al. 2001. The population biology of invasive species. Annu. Rev. Ecol. Syst. 32:305-332.

SAS Institute. 2009. SAS/STAT Version 9.0. SAS Institute, Cary, NC.

Schierenbeck, K. A. 2004. Japanese honeysuckle (Lonicera japonica) as an invasive species: history, ecology, and context. Cr. Rev. Plant Sci. 23:391400 .
Schierenbeck, K. A., J. L. Hamrick, and R. N. Mack. 1995. Comparison of allozyme variability in a native and an introduced species of Lonicera. Heredity 75:1-9.

Sexton, J. P., P. J. McIntyre, A. L. Angert, and K. J. Rice. 2009. Evolution and ecology of species range limits. Annu. Rev. Ecol. Evol. Syst. 40: $415-436$.

Siemann, E. and W. E. Rogers. 2001. Genetic differences in growth of an invasive tree species. Ecol. Lett. 4:514-518.

Simmons, A. D., and C. D. Thomas. 2004. Changes in dispersal during species' range expansions. Am. Nat. 164:378-395.

Skulman, B. W., J. D. Mattice, M. D. Cain, and E. E. Gbur. 2004. Evidence for allelopathic interference of Japanese honeysuckle (Lonicera japonica) to loblolly and shortleaf pine regeneration. Weed Sci. 52:433-439.

Theoharides, K. A., and J. S. Dukes. 2007. Plant invasion across space and time: factors affecting nonindigenous species success during four stages of invasion. New Phytol. 176:256-273.

Vos, P., R. Hogers, M. Bleeker, M. Reijans, T. van de Lee, M. Hornes, A. Frijters, J. Pot, J. Peleman, M. Kuiper and M. Zabeau. 1995. AFLP—a new technique for DNA fingerprinting. Nucleic Acids Res. 23:44074414.

Associate Editor: P. Tiffin

\section{Supporting Information}

Additional Supporting Information may be found in the online version of this article at the publisher's website:

Figure S1. Likelihood of genetic group number $(\mathrm{K})$ for Lonicera japonica sampled in the core and margin of the invaded range. 

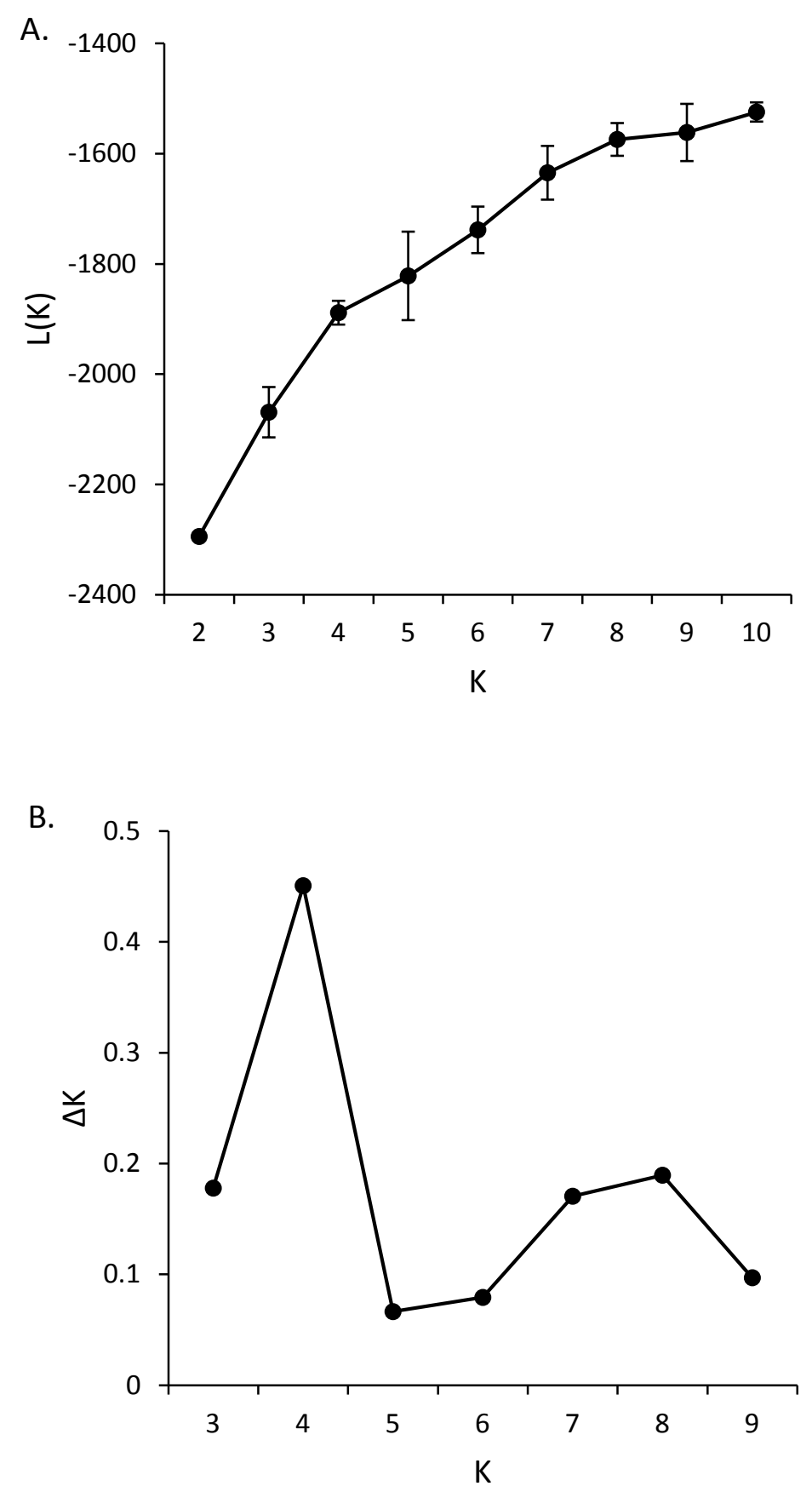

Supplemental Figure 1. Likelihood of genetic group number (K) for Lonicera japonica sampled in the core and margin of the invaded range. A range of $\mathrm{K}$ values were tested in the program Structure using 10 simulations for each $\mathrm{K}$ value $( \pm$ S.D., A). The likelihood that a particular group number is correct given the data is indicated by $\Delta \mathrm{K}(\mathrm{B})$. 